\title{
Nutraceuticals as Chemopreventive and Therapeutic agents in Gut Associated Pathogenesis
}

Irfan Ahmad', Md. Nasiruddin², Md. Asad Khan', Md. Zafaryab', Syed Hassan Mehdi ${ }^{1}$ and Md. Moshahid A Rizvi ${ }^{1 *}$

${ }^{1}$ Genome Biology Lab, Department of Biosciences, Jamia Millia Islamia, New Delhi

${ }^{2}$ Centre for Cellular and Molecular Platforms (C-CAMP), NCBS-TIFR, GKVK Campus, Bellary Road, Bangalore, India

\begin{abstract}
Nutraceuticals have gained great insights in recent years due to their therapeutic implications. Secondary metabolites like glutamate, flavonoids, polyphenols and terpenoids are widespread in nature and are part of human diet. Polysaccharides of prebiotic nature are used both as therapeutic and prophylactic agents. These nutraceuticals in recent times have been reported to posses great potential to reduce antigenic and oxidative pressure in the human gut. Antioxidant rich diet is a potential therapeutic agent against reactive oxygen species induced pathogenesis. Epegenetic compounds present in antioxidant and prebiotics rich nutraceuticals mitigate and remove the causative factors associated with pathogenesis. Flavonoids and polyphenols exhibit antioxidant properties and have been recognized as potential gastroprotective agents and epigenetic modulators as well. Triterpenoids such as cucurbitacin is reported to posses anticancer activities. Glutamate is an enteric neurotransmitter that is used in improving neonatal gut function. This review comprehensively summarizes the current knowledge of gut modulating nutraceuticals which ultimately can play its role from prophylaxis of gut to its therapeutics by employing various macro and micro molecular pathways.
\end{abstract}

Keywords: Nutraceutical; Gut pathogenesis; Secondary metabolites; Epigenetic modulators

\section{Introduction}

Dietary supplements composed of bioactive components of therapeutic importance are claimed as nutraceutical. The term is the combination of two words "nutrition and phamaceutical". This term was coined by Stephen L. De Felice in 1989 [1]. Nutraceuticals have emmerged as potential prophylactic/therapeutic modality for prevention and cure of a number of diseases. Epigenetic modulators present in nutraceuticals have been recognized as potential anti-cancer therapeutic agent $[2,3]$. Secondry metabolites obtained from the dietary plants are the basic source of nutraceuticals epegetic food. These epigenetic nutraceuticals play an important role in augmenting human health. Nutritional deficiencies can affect our body's immune response, neuroendocrine/exocrine secretions and gastrointestinal (GI) repair system. In their absence health related problems arise that lead to progression of pathogenesis. Plants are basic source of nutraceuticals. Combined intake of fruits and vegetables is found to be associated with improved anti-inflammatory and anti-oxidant status [4]. The World Health Organization (WHO) has found that inadequate intake of fruits and vegetables is one of the leading cause of chronic disease and major cause of mortality around the world [5,6]. These nutraceuticals have direct impacts on gut microflora which plays the most crucial role in GI function. Dietary habits of an individual have been found to be linked with the gut-associated microbial activities. Microbial processing of fruits, vegetables and metabolites in the gut modulate GI functions and therefore maintain good health. Receptors on GI neuronal cell membrane might be capable of recognizing specific molecules present in food that trigger the signals involved in peristalsis and gut motility. This determines functional response of intestine in terms of normal gut motility or abnormal movement of the gut leading to the physiological alterations like vomiting. Dietary nutritional components have capacity to modulate mucosalimmunity, neuroendocrine functions, serotonergic metabolism, hypothalamic-pituitary-adrenal-axis and inflammatory cytokines [7]. Anti-inflammatory flavonoids and other polyphenols have been reported to be greatly beneficial in improving enteric and systemic milieu [8,9]. Pharmacological effects of triterpenoids have also been reported in several studies which modulate immune system.
Triterpenoids act through intrinsic mode of apoptotic pathway to prevent tumor progression. Anticancer and anti-inflammatory effects of other secondary metabolites such as cucurbitacins have been extensively studied in targeting cyclin B1, cyclin D1, Mcl-1, cdc25C, STAT3 and p53 [10-15]. Glutamate an important constituent of dietary proteins is reported to improve intestinal barrier function and is also used as therapeutic agent for functional improvement of developing infant gut $[16,17]$. Dietary epigenetic compounds have been reported to be associated with prevention and treatment of various GI ailments, cardiovascular diseases and cancer $[18,19]$.

Basic sources of epigenetic compounds are fruits, vegetables and probiotics. Probiotics are microbial symbionts which colonize in different ecological niche in the gut and exist predominantly since the birth of an individual. Co-evolution of profound and diverse cellular and metabolic processes of the gut microflora modulates physiology and metabolism of the gut [20]. The genetic composition of enteric microbes helps them to synthesize certain enzymatic profile which is entirely different from the host enzymatic profile. This otherwise helps the host to broden the nutritional substratum. This symbiotic association between the host gut and microbial flora therefore, has a great significance [21-23].

Continuous repair and renewal of intestinal epithelium is required for maintenance of the homeostasis of mucosal epithelial layer of the villi and its integrity which depends on the production of new cells or by apoptosis $[24,25]$. To maintain a healthy as well as functionally efficient

*Corresponding author: Md. Moshahid A Rizvi, Genome Biology Lab, Department of Biosciences, Jamia Millia Islamia, New Delhi, Tel: +91-9911661657; E-mail: rizvi_ma@yahoo.com

Received: June 23, 2016; Accepted: October 21, 2016; Published October 25 2016

Citation: Ahmad I, Nasiruddin M, Khan MA, Zafaryab M, Mehdi SH, et al. (2016) Nutraceuticals as Chemopreventive and Therapeutic agents in Gut Associated Pathogenesis. Biochem Anal Biochem 5: 298. doi: 10.4172/2161-1009.1000298

Copyright: ( 2016 Ahmad I, et al. This is an open-access article distributed under the terms of the Creative Commons Attribution License, which permits unrestricted use, distribution, and reproduction in any medium, provided the original author and source are credited. 


\begin{tabular}{|l|l|}
\hline Nutraceuticals & Effects \\
\hline 1. Prebiotics & Modulation of enteric microbiome by concurrently improving population of enteric symbionts and suppression of opportunistic pathogens. \\
\hline 2. Polyphenols & Gastroprotection, antioxidation, immunomodulation, antitumor, anti-diabetic, anti-malarial, antimicrobials and anti-helminthic agents [34,51,54]. \\
\hline 3. Flavonoids & Anti-microbial, anti-viral, anti-inflammatory, hepatoprotection, cardioprotection, antioxidant, anti-cancer and anti-thrombogenic [55,34]. \\
\hline 4. Triterpenoids & Target inflammatory pathways and inhibition of tumorigenesis [56]. \\
\hline
\end{tabular}

Table 1: Therapeutic effect of some important nutraceuticals.

GI tract, factors that regulate various metabolic and physiological process should be balanced [26]. The main player among that factors are enteric microbiota, gastrointestinal mucosa, mucosal immunity, gut-brain axis, digestive enzymes and gastrointestinal neurosecretory hormones. Under the present article we therefore, have attempted to review the biomedical application of gut modulating nutraceuticals.

\section{Modulation of GI function by interactive action of symbionts and nutraceuticals}

Gut-associated microbiome modulates enteric functions in various ways. Neonates have a sterile guts. It normally aquire microorganisms through the environment of birth canal. Breast fed babies are known to have better health than the formula fed infant. This happen mainly due to healthy and balanced microbial colonization among the breat fed individuals. Nutraceuticals augment health among the individuals in all age groups from infant to adults. The dietary component of nutraceuticals are estabilished to improve the microbial biota of the gut, there by, ensuring a healthy gut. During the course of microbial degradation of undigested food molecules/particles by the microbes, multiple by products are generated which ultimately upgrades the host nutrional status.

Mucosal development is linked with a balanced microbial population of symbiotic nature in the gut. Gut-associated symbionts are known to have co-existed and co-evolved that compete for adherence with GI epithelial surface $[27,28]$. Neonatal gut however is more susceptible to the pathogenic challenges. Host-microbe interactions are essential for the development of mucosal immunity and enteric neurohormonalfunction. Germ free (GF) animals have impaired and undeveloped gut. GF animals have hypoplastic Peyer's patches, reduced number of plasma cells, abnormal spleen and lymph nodes, and impaired capillaries in intestinal villi. Restoration of these deficiencies is achieved by colonization of a single Bacteroides species [29-31]. These facts support the therapeutic use of probiotic bacteria. Probiotic-based metabolite like short chain fatty acids have been recognized as an energy source for gut mucosa its immune immunity and associated epigenetic modulations [32].

Probiotics have co-evolved their metabolic or biochemical pathways to utilize available undigested gut nutrients for their own benefit and extend additional nutritional pool for the host as their by product. These probiotics are capable of fermenting non digestible polysaccharides into digestible carbohydrates, SCFAs (short chain fatty acids), amino acids and vitamins [21]. This can be achieved by taking the example of germ free animals which are not capable of synthesizing vitamin $\mathrm{K}$ and certain species of vitamin $B$, while the conventionally colonized animals synthesize these components by employing different symbiotic microbial genus like Bacteroides and Eubacterium [33,34]. A healthy microbiome in the gut augments good health. Therefore, gut-associated normal flora needs to be protected by balanced dietary habits.

Human diet that can protect enteric normal flora is considered to be mandatory for good health. Under certain specific circumstances like chemotherapy and radio therapy microbial homeostasis is disrupted which can normally be reverted through therapeutic intervention of prebiotic-rich nutraceuticals. Gut modulating nutraceuticals have broad spectrum activities to augment enteric and systemic health (Table 1). Dietary cucurbits are the nutraceuticals that have been reported to contain adequate amounts of nutraceuticals of antioxidant and have prebiotic nature including sitotherapeutic potentials $[26,35,36]$. Prebiotic polysaccharides in the diet get hydrolyzed by probiotics. Mammals are capable of hydrolyzing disaccharides and absorb monosaccharides, such as glucose and galactose, but they cannot break-down complex carbohydrates such as cellulose, inulin and inulin like polysaccharides. Certain enteric bacteria have potential to synthesize enzymes for the digestion of these polysaccharides. According to the recently revolved functional genomics of "Bacteroides thetaiotaomicron" 400 different enzymes are encoded play crucial role in various cellular activities including digestion of complex sugars [20], and well-understood starch utilization system $[37,38]$. Gut-associated microbiome regulates fat storage in the host. It also promotes the absorption of monosaccharides from the gut lumen and induce hepatic lipogenesis [39]. Studies on animals and humans are highlighted the important roles for bacterial signals in promoting the digestion of food, modulation of fat metabolism, epithelial homeostasis, angiogenesis, enteric nervous system, resistance to infection and regulation of gut associated immunity $[37,39,40-44]$. Recent investigations on animal models and in vitro studies have revealed that enteric microbiome regulates host cell metabolic pathways to maintain health and nutritional outcomes of the host [45-47]. Butyrate alongwith some species of probiotic Lactobacilli improve GI epithelial barrier integrity by modulating the expression of certain tight junction proteins [48-50]. Many species of probiotic Lactobacilli and Bifidobacteria are capable of secreting broad spectrum bacteriocins (natural antibiotics) which inhibit or attenuate pathogenic microbes and therefore, modulate innate immunity. Other mechanisms through which Lactobacilli assists its functions include an immune stimulation, competition for nutrients and blocking of pathogen adhesion on the gut surface.

Many intestinal pathogens like type 1 fimbriated Escherichia coli, Salmonella and Campylobacters utilize oligosaccharide receptor sites in the gut. After recognition of these oligosaccharide receptor sites in gut, these bacteria activate a cascade of pathogenesis and cause gastroenteritis through invasion as well as toxin production. H. pylori infection of the gastric mucosa induces a colitogenic condition which further transform into ulcerative colitis, adenocarcinomas and gastric B-cell lymphomas. Dietary polyphenols (DPs) act against various strains of $H$. pylori [51]. DPs protect the gut by modulating gut physiology and metabolisms and by inhibiting the growth or killing the pathogens. Curcumin is one of the most studied DPs having broad spectrum antimicrobial and anti-malarial activities [52,53]. The ability of gut microbiota to communicate with the brain has emerged as an exciting field in modern health sciences [54-56]. The intestinal microbiota influences the gastrointestinal physiology, including its development and enteric nervous system [54]. Nutraceuticals have great impact on enteric as well as systemic metabolisms and association with the enteric microbiomes to ensure better health. Extensive research on diet-microbiome-gut interactions and their influence on enteric as well as systemic functions are still needed. 


\begin{tabular}{|l|l|}
\hline Function & Target \\
\hline 1. Growth modulator & Increase jejunal villus height, mucosal thickness and intestinal epithelial cell proliferation [68]. \\
\hline 2. Energy source & Gut-associated lymphoid tissues (GALTs) and intestinal epithelial cells (IECs) [69]. \\
\hline 3. Immunoglobulins enhancer & Purified B-cells and peripheral mononuclear cells were found to produce more IgG and IgE when cultured with glutamate in vitro [70]. \\
\hline 4. Precursor & L-alanine, L-aspartate, L-ornithine, L-proline and glutathione (GSH) production [71]. \\
\hline
\end{tabular}

Table 2: Effect of glutamate in gastrointestinal tract.

\section{Augmentation of gut development by dietary glutamate}

The inherited genetic and epigenetic blue prints associated with GI stem cells are capable of maintaining cellular proliferation dynamics in the gut. The diet of the mother can have long-term impacts on the health of her offspring, possibly through inherited diet-induced chromatin alterations. Intestinal mucosa exhibits high rates of proliferation and rapid cell migration. Intestinal crypt stem cells proliferated through mitosis survive only two to four days before their migration to the tip of the villi which are ultimately extruded [57]. Glutamic acid is one of the most abundant amino acids normally present in many proteins and peptides. Glutamate, a derivative of glutamic acid is the major oxidative fuel for the gut. Glutamate is also a potent enteric neurotransmitter; important precursor for synthesis of bioactive molecules and a potential therapeutic agent for improving neonatal gut function [58-61]. The premature neonatal gut exhibits a high rate of cellular proliferation and replacement in gut epithelia. Ill functioning gut limits the ability to provide critically important enteric nutrition $[62,63]$.

Mother milk is a rich source of glutamate. Infant's formula milk also contain adequate amount of glutamate. Glutamate has the capacity to enhance food intake in old aged individual. Diet free from glutamate evokes visceral sensation from the stomach, intestine and portal vein. The concentration of glutamate in blood is reported to be lowest because most of the glutamate is absorbed and consumed by GI epithelium during transcellullar transport from the gut lumen [64]. Large number of transporter molecules are expressed in epithelial cells of gastric lining but only few of them are involved in glutamate transport system $[65,66]$. Glutamate activates contractile action in the gastric fundus possibly via cholinergic neurons $[58,59,67]$.

Glutamate is also found to be linked with immunomodulatory effect on gut-associated lymphoid tissues (GALT) to optimize the immune function (Table 2). It is oxidative substrate for immune cells and intestinal epithelial cells [68-71]. Therefore, adequate amount of glutamate in the diet influence metabolic and physiological outcome to augment GI health.

\section{Impact on the gut-brain-axis or enteric nervous system}

Gastrointestinal function is controlled and coordinated by enteric neuroendocrine and exocrine components in association with central nervous system (CNS). Efficient digestion of food, absorption and excretion are primary function of the gut which is facilitated through enteric exocrine, endocrine secretions and entero-neuro-endocrine sponsored gut motility. The signal for appetite originate from the gutbrain axis and received by central nervous system (CNS) which in turn regulates the intake of food to maintain food-energy input and expenditure. The most crucial role of gut-brain axis is to connect the brain with neuroendocrine centre and, enteric nervous system leading to multicomponent bidirectional communication network [72]. Amount and nature of the diet also influence GI cellular proliferation.

Deficiency of essential nutrients including dietary polyphenols is associated with enteric neurohormon dysregulation, immunodeficiencyas well as disbalenced microbial composition in the gut leading to alteration in individual's natural ability to resist against gut-associated pathogenesis [73-76]. Gut pathogenesis such as irritable bowel syndrome, neoplastic development, diabetes, obesity, and cardiovascular diseases are normally initiated due to the nutritional deficiencies of certain bioactive components like modulator of enteric neurohormones and innate/adaptive immunity. Accumulation of exogenous and endogenous oxidants at the surface of the gut wall induce degenerative signal resulting into neuronal damages of enteric nervous system. These degenative signals trigger leading to gut pathogenesis. Antioxidant rich nutraceuticals play a protective role against oxidative damage of enteric neurons. Nutraceuticals like flavonoids and polyphenols mitigate reactive oxygen species [36]. There is a great scope for investigations on the nutraceuticals and their implications in gut-associated functions.

\section{Antioxidant defense system}

Antioxidant defence mechanism scavenge reactive oxygen species (ROS) to protect the host against oxidative stress. Intake of antioxidant deficient diet may lead to pathogenesis due to accumulation of intrinsic and extrinsic oxidative burden in enteric as well as systemic parts of the body. The consumption of an adequate amount of fruits and vegetables are linked with ROS scavenging potential and improvement of antioxidant defense status [4,72]. Antioxidants defence system acts against oxidative stress at different levels through diverse mechanisms [77].

Free radical scavenging occurs by two methods- (i) non-enzymatic action (chemical method) and (ii) enzymatic action. Nutraceuticals like polyphenols and flavonoids are the players under the non-enzymatic action. Endogeneously synthesized enzymes such as superoxide dismutase (SOD), catalase (CAT), and glutathione peroxidase (GPx or GSH-Px) are the players under enzymatic action. SOD and CAT act primarily in the cytoplasm and form the first line of defense against oxidants [78]. A growing line of evidence suggests that imbalances in the ratio of oxidant/antioxidant induces lipid peroxidation. Enhanced levels of thiobarbituric acid reactive substances (TBARS) with simultaneous depletion of various antioxidant enzymes are found in several cancer types of like cervical, oral, breast, prostate and Hodgkin's lymphoma [79-84]. Balanced food containing antioxidant rich nutrients modulate antioxidant defense mechanisms and display better health. The concept of developing biomedicine/epigenetic diet to prevent gut-associated pathogenesis requires identification of broad spectrum gastroprotective epigenetic nutraceuticals. Plant derived dietary extracts have been found to show their broad spectrum activities such as antioxidant properties, prebiotic action and modulation of proton pumping ATPase $[35,85]$. Extracts of green tea, broccoli sprouts, turmeric and soybean have been reported for their broad spectrum biological activities including antioxidant properties and epigenetic regulators in gut associated cancers $[2,3,86]$. These have been recognized as epigenetic diet (Table 3 ).

\section{Nutraceuticals Employed in Cancer Therapeutics}

In recent years, an array of experimental evidence has underlined the importance of traditional medicines which have been served through ages for prevention and treatment of various types of chronic 
Citation: Ahmad I, Nasiruddin M, Khan MA, Zafaryab M, Mehdi SH, et al. (2016) Nutraceuticals as Chemopreventive and Therapeutic agents in Gut Associated Pathogenesis. Biochem Anal Biochem 5: 298. doi: 10.4172/2161-1009.1000298

Page 4 of 8

\begin{tabular}{|l|l|}
\hline Epigenetic modulators & Activity at the target \\
\hline 1. Curcumin & Reactivation of epigenetically silenced gene (demethylation of DNA), inhibits HDAC1, HDAC3, p300 and p300 HAT activity [98,106-108]. \\
\hline 2. Genistein (Phytoestrogens) & Inhibition of DNM, reactivation of epigenetically silenced genes (p16INK4a, RAR beta, and MGMT) [100,109]. \\
\hline 3. Epigallocatechin (EGCG) & Inhibition DNMTs, modulate expression of 16-miRNA and inhibit HDAC \\
\hline 4. Apple polyphenols & Inhibition DNMT and reactivate epigenetically silenced TSGs [112]. \\
\hline 5. Resveratrol & Activation class III HDACs [113]. \\
\hline 6. SCFAs & Histone deacetylase inhibitors (HDACi) [114-116,15]. \\
\hline 7. Butyrate & Epigenetic remodeling and the expression of pluripotency-associated genes of stem cell derived from human adult or fetal fibroblasts [117]. \\
\hline 8. Sodium butyrate & Modulate expression of cathelicidin gene by regulating activator protein 1 (AP-1) and histone acetylation of cathelicidin promoter [118]. \\
\hline
\end{tabular}

Table 3: Chemopreventive epigenetic modulators from dietary plants and probiotics.

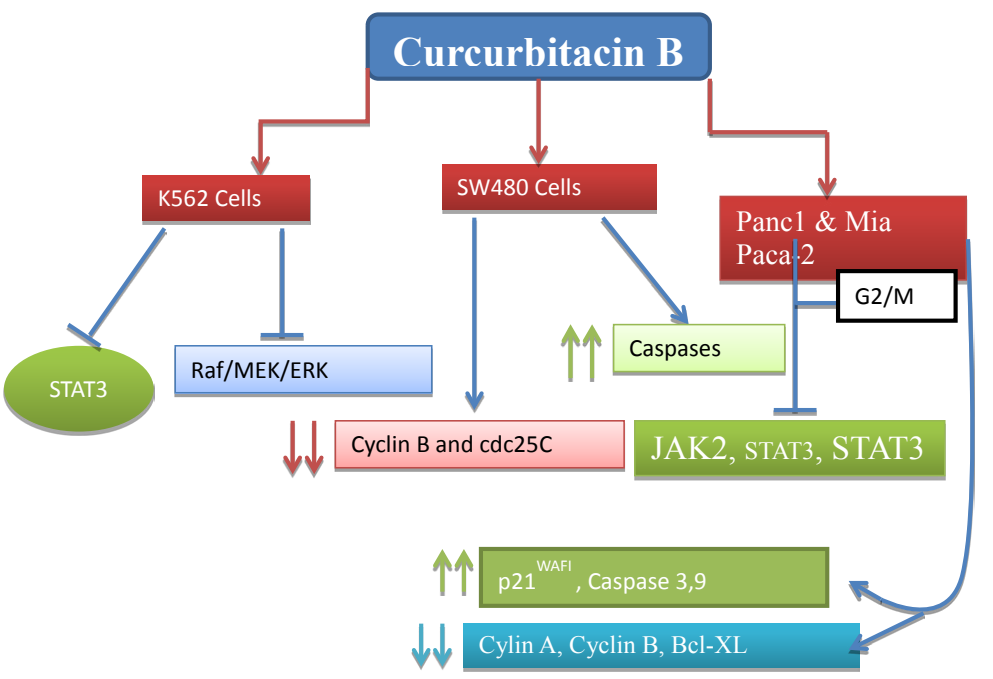

Figure 1: Molecular mechanism involved in CuB mediated anti-proliferative effects on cancer cells.

ailments. Gastroprotective nutraceuticals such as triterpenoids, flavonoids and polyphenols have also been reported to be meaningful in the treatment of various types of cancer.

\section{Triterpenoids}

Fruits and vegetables are rich source of triterpenoids. Cucurbetatious plants contain adequate amount of cucurbitacins which act as microbicidal, anti-inflammatory and anticancer. CucurbitacinB $(\mathrm{CuB})$ is one of the most studied member of triterpenoids. Its anticancer effect has been seen on different leukemia cell lines. Role of $\mathrm{CuB}$ as antiproliferative agent on K562 cells through STAT3 activation and the regulation of Raf/MEK/ERK pathway have been reported [10]. Further, study on the K562 cell line demostrated that cucurbitacin B act as regulator of STAT3 activation and RAf/MEK/ERK pathway. Type of Cucurbitacine B isolated from Thai herb Trichosanthes cucumerina $L$. is reported to be growth inhibitor of breast cancer through supression of hTERT and cMy-c expression). Meixia et al. have demonstrated its $(\mathrm{CuB})$ anticancer effect in pancreatic cancer cells by inhibition of STAT3 phosphorylation, activation of caspase3, up-regulation of p21, p53 and down regulation of both survivin as well asBcl-2 [87]. The in vivo study has revealed the anticancer effect of this compound through by mechanism associated with inhibitory effect on JAK2/ STAT3 and decreased expression of Bcl-XL whereas, the expression of caspase 3 and caspase 9 was found to be upregulated [14]. Cucurbitacin $\mathrm{B}$, isolated from Trichosanthes cucumerima L. has been found to act as immunomodulatory which effectively inhibits the expression of CD69+CD3+, and CD25+CD3+ on PHA-stimulated human peripheral blood mononuclear cells (PBMCs). Molecular mechanisms of $\mathrm{CuB}$ has been summarized shown in the figure (Figure 1).

\section{Flavonoids}

Studies made on flavonoids have revealed that have certain anticancer effect. Apigenin is a well studied dietary flavonoid available in fruits band vegetables and been reported to act as a therapeutic agent in various types of diseases including cancer [88]. It has been repoted that apigenin have also demonstrated the growth inhibitory effect on different cancers like leukemia, colon, prostate, thyroid, skin, breast as well as lung cancer [89-95]. It is also reported that apigenin inhibits the lung cancer growth via supression of expression of vascular endothelial growth factor (VEGF), trnscription activation of the hypoxia-inducible factor-1 (HIF-1) binding site through p70S6K1 activation and AKT inhibition [95]. HIF-1 and VEGF have been reported as inducers of angiogenesis. Apigenin acts as anti-angiogenesis in mice by inhibition of expression of HIF-1 and VEGF in lung cancer [95] (). Apigenin has also been reported as apoptosis inducer through the up regulation of FADD expression through the induction of phosphorylation in colorectal cancer cells and plays an anticancer role against colon cancer by direct binding and inhibitionof RSP9 (identified ribosomal protein S9) which leads to the activation of CDK1 [96,97]. In addition , epigenin acts as anti-inflammatory and antioxidant agents [98]. the above studies establish the importance of these nutraceuticals and now these doesnot seem to any dout that these nutraceutical compounds may be given to the cancer patient as dietary supplement to reduce progression of tumor. Disease-specific formulation of nutraceuticals might emerge as new therapeutic suppliment in future (Figure 2).

\section{Polyphenols Act as Potent Epigenetic Modulators}

Epigenetic alterations in pathogenesis like cancer have evolved as 
Citation: Ahmad I, Nasiruddin M, Khan MA, Zafaryab M, Mehdi SH, et al. (2016) Nutraceuticals as Chemopreventive and Therapeutic agents in Gut Associated Pathogenesis. Biochem Anal Biochem 5: 298. doi: 10.4172/2161-1009.1000298

Page 5 of 8

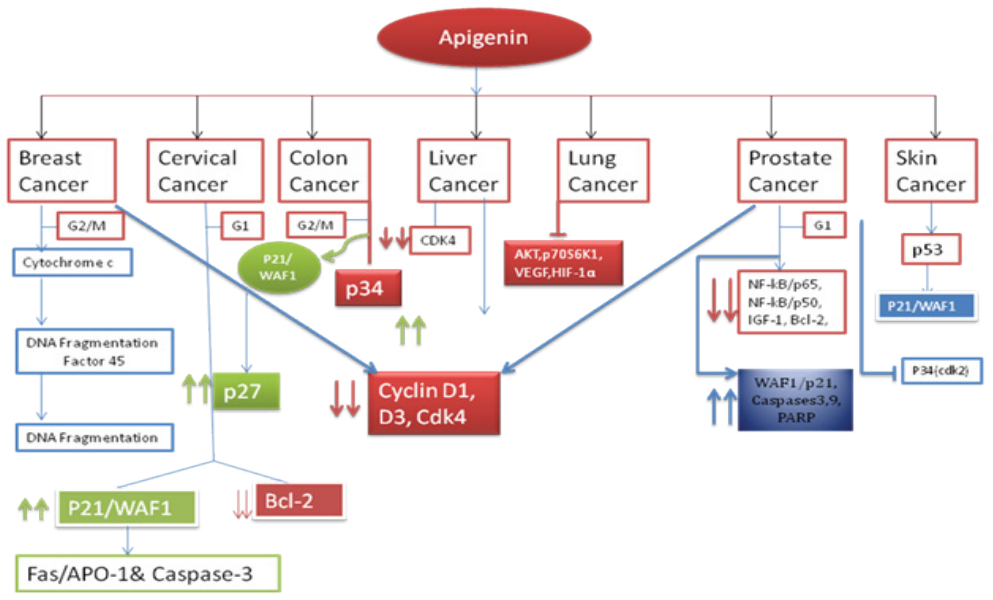

Figure 2: Apigenin showing its molecular mechanisms in growth inhibition of different type of cancer.

possible target for therapeutic intervention. Epigenetically silenced gene due to either DNA methylation (promoter hypermethylation of cytosines at CpG islands) and histone modifications (acetylation, phosphorylation and methylation) may be reactivated because these alterations are reversible. Hypermethylations within $\mathrm{CpG}$ islands of tumor suppressor genes (TSGs) have recently been reported to be associated with pathogenesis of various cancer types [99-101]. Out of various polyphenols, curcumin is one of the most widely studied DPs for its therapeutic use as an epigenetic drug for the treatment and prevention of different types of cancer including colorectal [102]. DPs like 2-epigallocatechin-3-gallate (EGCG) isolated from green tea and genistein isolted from soybean have been found to inhibit DNMT activity against cancer cell lines [103,104]. DNMT inhibitory activity is associated with reactivation of epigenetically silenced genes such as p16, RARb, MGMT, MLH1, BTG3 and GSTP1 in human cancer cells, suggesting a possible alternate phytotherapeutic modality by targeting epigenetically silenced tumor suppressor genes through dietary polyphenols [104,105]. Curcumin has also been reported to exhibit epigenetic modulation in cancer cells by histone acetyltransferase (HAT) and DNMT1 inhibition activities [106-109]. Intake of polyphenols rich nutraceuticals, therefore, protects human gut from malignant transformation.

\section{Conclusion and Future Prospects}

The studies on gut-nutrient-microbiome interactions and their consequences have thrown light towards better understanding of metabolic and physiological modulation of GI functions. Human health largely depends on a healthy enteric system which may be maintained by regular intake of fruits and vegetables [110-115]. Dietary nutrients, probiotics and metabolites derived from enteric symbionts are now established for their utility in improving, gut physiology, immunity, and ultimately a better health. Nutraceuticals such as glutamate, polyphenols, flavonoids, prebiotics, probiotics and SCFAs have now been recognized as potential therapeutic and prophylactic agents to cure various gut-associated ailments. Epigentic nutraceuticals have recently been implicated for prevention and therapy of a number of diseases and cancers. Disruption of either balanced gut-brain axis or the gut microbiome interactions by inappropriate dietary habits and chemotherapeutic intervention caused dysregulation of GI function resulting into the progression of gut pathogenesis. A balanced combination of diet containing epigenetic nutaceuticals and food based probiotics not only can save from various gut pathogenesis rather it can act as prophylactic. The role of epigenetic nutraceuticals in the alterations of epigenetic composition of human genome leaves a great future for the researchers in the field [116-122]. Further understanding of molecular cross talk of epigenetic nutraceuticals with the microbiome epigenome and cellular millue of gut can lead to the development of disease specific formulations of natural mrdicine. This will open new vistas in therapeutics.

\section{Acknowledgment}

Financial assistance provided to IA from Defense Research and Development Organization (DRDO) through an MRP and UGC fellowship is acknowledged. Indian Council of Medical Research (ICMR), Govt. of India is also acknowledged for financial assistance to $\mathrm{MZ}$.

\section{References}

1. Kalra EK (2003) Nutraceutical-definition and introduction. AAPS pharm Sci 5 27-28.

2. Meeran SM, Ahmed A, Tollefsbol TO (2010) Epigenetic targets of bioactive dietary components for cancer prevention and therapy. Clin Epigenetics 1: 101-116.

3. Hardy TM, Tollefsbol TO (2011) Epigenetic diet: impact on the epigenome and cancer. Epigenomics 3: 503-518.

4. Root MM, McGinn MC, Nieman DC, Henson DA, Heinz SA et al. (2012) Combined fruit and vegetable intake is correlated with improved inflammatory and oxidant status from a cross-sectional study in a community setting Nutrients 4: 29-41.

5. WHO (World Health Organization) (2002) The World Health Report 2002 Reducing risks to health, Promoting healthy life; World Health Organization 2002 Geneva, Switzland.

6. Lock K, Pomerleau J, Causer L, Altmann DR, McKee M (2005) The global burden of disease attributable to low consumption of fruit and vegetables: implications for the global strategy on diet. Bull. World Health Organ 83: 100-108.

7. Brummer RJM (2005) Nutritional modulation of the brain gut axis. Scandinavian Journal of Nutrition 49: 98-105.

8. Pimple BP, Kadam PV, Patil MJ (2012) Protective effect of Luffa acutangula extracts on gastric ulceration in NIDDM rats: role of gastric mucosal glycoproteins and antioxidants. Asian Pac J Trop Med 5: 610-615.

9. Gonzalez R, Ballester I, Lopez-Posadas R, Suárez MD, Zarzuelo A, et al (2011) Effects of flavonoids and other polyphenols on inflammation. Crit Rev Food Sci Nut 51: 331-362.

10. Chan KT, Li K, Liu SL, Chu KH, Toh M, et al. (2010) Cucurbitacin B inhibits STAT3 and the Raf/MEK/ERK pathway in leukemia cell line K562. CancerLetters 289 46-52.

11. Lui VW, Yau DM, Wong EY, Ng YK, Lau CP, et al. (2009) Cucurbitacin-I elicits anoikis sensitization, inhibits cellular invasion and in vivo tumor formation ability of nasopharyngeal carcinoma cells. Carcinogenesis 30: 2085-2094. 
Citation: Ahmad I, Nasiruddin M, Khan MA, Zafaryab M, Mehdi SH, et al. (2016) Nutraceuticals as Chemopreventive and Therapeutic agents in Gut Associated Pathogenesis. Biochem Anal Biochem 5: 298. doi: 10.4172/2161-1009.1000298

12. Sun C, Zhang M, Shan X, Zhou X, Yang J, et al. (2009) Inhibitory effect of cucurbitacin E on pancreatic cancer cells growth via STAT3 signaling. J Cancer Res Clin Oncol 136: 603-610.

13. Sun J, Blaskovich MA, Jove R, Livingston SK, Coppola D, et al. (2005) Cucurbitacin Q: A selective STAT3 activation inhibitor with potent antitumor activity. Oncogene 24: 3236-3245

14. Thoennissen NH, Iwanski GB, Doan NB, Okamoto R, Lin P, et al. (2009) Cucurbitacin $B$ induces apoptosis by inhibition of the JAK/STAT pathway and potentiates antiproliferative effects of gemcitabine on pancreatic cancer cells. Cancer Res 69: 5876-5884

15. Yasudam S, Yogosawa S, Izutani $Y$, Nakamura $Y$, Watanabe $H$, et al. (2009) Cucurbitacin B induces $G(2)$ arrest and apoptosis via a reactive oxygen species-dependent mechanism in human colon adenocarcinoma SW480 cells. Mol Nutr Food Res 54: 559-565.

16. Bertin S, Pierrefite-Carle V (2008) Autophagy and toll-like receptors: A new link in cancer cells. Autophagy 4: 1086-1089.

17. Ewaschuk JB, Murdoch GK, Johnson IR, Madsen KL, Field CJ (2011) Glutamine supplementation improves intestinal barrier function in a weaned piglet model of Escherichia coli infection. Br J Nutr 106: 870-877.

18. Romier B, Schneider YJ, Larondelle Y, During A (2009) Dietary polyphenols can modulate the intestinal inflammatory response. Nutr Rev 67: 363-378.

19. Reuter S, Gupta SC, Park B, Goel A, Aggarwal BB (2011) Epigenetic changes induced by curcumin and other natural compounds. Genes Nutr 6: 93-108.

20. Martin FP, Sprenger N, Yap IK, Wang Y, Bibiloni R, et al. (2009) Panorganisma gut microbiome-host metabolic crosstalk. J Proteome Res 8: 2090-2105.

21. Xu J, Bjursell MK, Himrod J, Deng S, Carmichael LK, et al. (2003) A genomic view of the human-Bacteroides the taiotao micron symbiosis. Science 299 2074-2076.

22. Pridmore RD, Berger B, Desiere F, Vilanova D, Barretto C, et al. (2004) The genome sequence of the probiotic intestinal bacterium Lactobacillus johnsoni NCC 533. Proc Natl Acad Sci USA 101: 2512-2517.

23. Hooper LV, Wong MH, Thelin A, Hansson L, Falk PG, et al. (2001) Molecular analysis of commensal host-microbial relationships in the intestine. Science 291: 881-884.

24. Madara JL (1990) Maintenance of the macromolecular barrier at cell extrusion sites in intestinal epithelium: physiological rearrangement of tight junctions. J Membr Biol 116: 177-184.

25. Hall PA, Coates PJ, Ansari B, Hopwood D (1994) Regulation of cell number in the mammalian gastrointestinal tract: the importance of apoptosis. J Cell Sci 107: 3569-3577.

26. Ahmad I, Irshad M, Rizvi MMA (2011) Nutritional and medicinal potential of Lagenaria siceraria. Int J Veg Sci 17: 157-170.

27. Tappenden KA, Deutsch AS (2007) The physiological relevance of the intestinal microbiota contributions to human health. J Am Coll Nutr 26: 679-683.

28. Flint HJ, Duncan SH, Scott KP, Louis $P$ (2007) Interactions and competition within the microbial community of the human colon: links between diet and health. Environ Microbio 9: 1101-1111.

29. Hooper LV (2004) Bacterial contributions to mammalian gut development. Trends Microbiol 12: 129-134.

30. Macpherson AJ, Harris NL (2004) Interactions between commensal intestina bacteria and the immune system. Nat Rev Immunol 4: 478-485.

31. Mazmanian SK, Liu CH, Tzianabos AO, Kasper DL (2005)An immunomodulatory molecule of symbiotic bacteria directs maturation of the host immune system. Cell 122: 107-118.s

32. Waldecker M, Kautenburger T, Daumann H, Busch C, Schrenk D (2008) Inhibition of histone-deacetylase activity by short-chain fatty acids and some polyphenol metabolites formed in the colon. J Nutr Biochem 19: 587-593.

33. Wostmann BS (1981) The germfree animal in nutritional studies. Annu Rev Nutr 1: $257-279$

34. Hill MJ (1997) Intestinal flora and endogenous vitamin synthesis. Eur J Cancer Prev 6: 43-45.

35. Irshad M, Ahmad I, Goel HC, Rizvi MMA (2010) Phytochemical screening and high performance TLC analysis of some cucurbits. Res J Phytochem 4: 242-247.
36. Irshad M, Ahmad I, Mehdi SJ, Goel HC, Rizvi MMA (2014) Anti-oxidant capacity and phenolic content of aqueous extract of commonly consumed cucurbits. In J Food Prop 00:1-8.

37. Hooper LV, Midtvedt T, Gordon JI (2002) How host-microbial interactions shap the nutrient environment of the mammalian intestine. Annu Rev Nutr 22: 283-307.

38. Cho KH, Cho D, Wang GR, Salyers AA (2001) New regulatory gene that contributes to control of Bacteroides the taiotao micron starch utilization genes. J Bacteriol 183: 7198-7205.

39. Backhed F, Ding H, Wang T, Hooper LV, Koh GY, et al. (2004) The gut microbiota as an environmental factor that regulates fat storage. Proc Natl Acad Sci USA 101: 15718-15723.

40. Artis D (2008) Epithelial-cell recognition of commensal bacteria and maintenance of immune homeostasis in the gut. Nat Rev Immunol 8: 411-420.

41. Stappenbeck TS, Hooper LV, Gordon JI (2002) Developmental regulation of intestinal angiogenesis by indigenous microbes via Paneth cells. Proc Nat Acad Sci U S A 99: 15451-15455.

42. Husebye E, Hellstrom PM, Midtvedt T (1994) Intestinal microflora stimulates myoelectric activity of rat small intestine by promoting cyclic initiation and aboral propagation of migrating myoelectric complex. Dig Dis Sci 39: 946-956.

43. Sekirov I, Tam NM, Jogova M, Robertson ML, Li Y, et al. (2008) Antibioticinduced perturbations of the intestinal microbiota alter host susceptibility to enteric infection. Infect Immun 76: 4726-4736.

44. Cebra JJ (1999) Influences of microbiota on intestinal immune system development. Am J Clin Nutr 69: 1046-1051.

45. Li M, Wang B, Zhang M, Rantalainen M, Wang S, et al. (2008) Symbiotic gut microbes modulate human metabolic phenotypes. Proc Natl Acad Sci U S A 105: $2117-2122$

46. Clayton TA, Baker D, Lindon JC, Everett JR, Nicholson JK (2009) Pharmacometabonomic identification of a significant host-microbiome metabolic interaction affecting human drug metabolism. Proc Natl Acad Sci USA 106: 14728-14733.

47. Wikoff WR, Anfora AT, Liu J, Schultz PG, Lesley SA, et al. (2009) Metabolomics analysis reveals large effects of gut microflora on mammalian blood metabolites. Proc Natl Acad Sci USA 106: 3698-3703.

48. Karczewski J, Troost FJ, Konings I, Dekker J, Kleerebezem M, et al. (2010) Regulation of human epithelial tight junction proteins by Lactobacillus plantarum in vivo and protective effects on the epithelial barrier. Am J Physiol Gastrointest Liver Physiol 298: G851-G859.

49. Bordin M, D'Atri F, Guillemot L, Citi S (2004) Histone deacetylase inhibitors upregulate the expression of tight junction proteins. Mol Cancer Res 2: 692-701.

50. Peng L, Li ZR, Green RS, Holzman IR, Lin J (2009) Butyrate enhances the intestinal barrier by facilitating tight junction assembly via activation of AMP activated protein kinase in Caco-2 cell monolayers. J Nutr 139: 1619-1625.

51. De R, Kundu P, Swarnakar S, Ramamurthy T, Chowdhury A, et al. (2009) Antimicrobial activity of curcumin against Helicobacter pylori isolates from India and during infections in mice. Antimicrob Agents Chemother 53: 1592-1597.

52. Feroz A, Rizvi MMA, Kar SK (2012) Oral delivery of curcumine bound to chitosan nanoparticles cured Plasmodium yoelii infected mice. Biotechnology Advance 30: 310-320.

53. Collins SM, Bercik P (2009) The relationship between intestinal microbiota and the central nervous system in normal gastrointestinal function and disease. Gastroenterology 136: 2003-2014.

54. Cryan JF, O'Mahony SM (2011) The microbiome-gut-brain axis: from bowel to behavior. Neurogastro Enterol Motil 23: 187-192.

55. Bahadoran Z, Mirmiran P, Azizi F (2013) Dietary polyphenols as potentia nutraceuticals in management of diabetes: A review. J Diabetes Metab Disord 12: 43

56. Potten CS, Grant HK (1998) The relationship between ionizing radiationinduced apoptosis and stem cells in the small and large intestine. $\mathrm{Br} \mathrm{J}$ Cance 78: 993-1003.

57. Jankovic SM, Milovanović D, Matovih M, Irić-Cupić V (1999) The effects of excitatory amino acids on isolated gut segments of the rat. Pharmacol Res 39: 143-148. 
Citation: Ahmad I, Nasiruddin M, Khan MA, Zafaryab M, Mehdi SH, et al. (2016) Nutraceuticals as Chemopreventive and Therapeutic agents in Gut Associated Pathogenesis. Biochem Anal Biochem 5: 298. doi: 10.4172/2161-1009.1000298

58. Giaroni C, Zanetti E, Marino F, Cosentino M, Senaldi A, et al. (2000) Glutamate receptors of the AMPA type modulate neurotransmitter release and peristalsis in the guinea-pig isolated colon. Life Sci 67: 1747-1757.

59. Uneyama H, Niijima A, San GA, Torii K (2006) Luminal amino acid sensing in the rat gastric mucosa. Am J Physiol Gastrointest Liver Physiol 291: G1163-G1170.

60. Hays SP, Ordonez JM, Burrin DG, Sunehag AL (2007) Dietary glutamate is almost entirely removed in its first pass through the splanchnic bed in premature infants. Pediatr Res 62: 353-356.

61. Berseth CL (2005) Feeding strategies and necrotizing enterocolitis. Curr Opin Pediatr 17: 170-173.

62. Neu J, Zhang L (2005) Feeding intolerance in very-low-birth weight infants: what is it and what can we do about it? Acta Paediatr Suppl 94: 93-99.

63. Blachier F, Boutry C, Bos C, Tomé D (2009) Metabolism and functions of L-glutamate in the epithelial cells of the small and large intestines. Am J Clin Nutr 90: 814-821.

64. Howell JA, Matthews AD, Welbourne TC, Matthews JC (2003) Content of ilea EAAC1 and hepatic GLT-1 high-affinity glutamate transporters is increased in growing vs. non-growing lambs, paralleling increased tissue $\mathrm{D}$ - and L-glutamate, plasma glutamine, and alanine concentrations. J Anim Sci 81: 1030-1039.

65. Kirchhoff P, Dave MH, Remy C, Kosiek O, Busque SM, et al. (2006) An amino acid transporter involved in gastric acid secretion. Pflugers Arch 451: 738-748.

66. Campbell BG, Couceyro P, Keana JF, Weber E (1991) N-methyl-D-aspartate receptor-mediated contractions of the guinea pig ileum longitudinal muscle/ myenteric plexus preparation: modulation by phencyclidine and glycine receptors. J Pharmacol Exp Ther 257: 754-766.

67. Wu X, Zhang Y, Liu Z, Li TJ, Yin YL (2012) Effects of oral supplementation with glutamate or combination of glutamate and $\mathrm{N}$-carbamylglutamate on intestinal mucosa morphology and epithelium cell proliferation in weanling piglets. J Anim Sci 90: 337-339.

68. Reeds PJ (2000) Dispensable and indispensable amino acids for humans. J Nutr 130: $1835-1840$

69. Sturgill JL, Mathews J, Scherle P, Conrad DH (2011) Glutamate signaling through the kainate receptor enhances human immunoglobulin production. $J$ Neuroimmunol 233: 80-89.

70. Reeds PJ, Burrin DG, Stoll B, Jahoor F, Wykes L, et al. (1997) Enteral glutamate is the preferential source for mucosal glutathione synthesis in fed piglets. Am J Physiol 273: 408-415

71. Mayer EA, Gebhart GF (1994) Basic and clinical aspects of visceral hyperalgesia. Gastroenterology 107: 271-293.

72. Tapas AR, Sakarkar DM, Kakde RB (2008) Flavonoids as nutraceuticals: A review. Trop J Pharm Res 7: 9-1099.

73. Yadav VR, Prasad R, Sung B, Kannappan R, Bharat BA (2010) Targeting inflammatory pathways by triterpenoids for prevention and treatment of cancer. Toxins 2: 2428-2466

74. Vauzour D (2012) Dietary polyphenols as modulators of Brain Functions: biological Actions and molecular mechanisms underpinning their beneficial effects. Oxid Med and Cell Longev 9: 142-173.

75. Nicholson JK, Holmes E, Kinross J, Burcelin R, Gibson G, et al. (2012) Host-gut microbiota metabolic interactions. Science 336: 1262-1267.

76. Halliwell B, Gutteridge JMC (2007) Free radicals in biology and medicine (4thedn). Oxford University Press, Oxford, UK.

77. Gago-Dominguez M, Castelao JE (2006) Lipid peroxidation and renal cel carcinoma: further supportive evidence and new mechanistic insights. Free Radic Biol Med 40: 721-733.

78. Kolanjiappan K, Manoharan S, Kayalvizhi M (2002) Measurement of erythrocyte lipids, lipid peroxidation, antioxidants and osmotic fragility in cervical cancer patients. Clin Chim Acta 326: 143-149.

79. Manju V, Balasubramanian V, Nalini N (2002) Oxidative stress and tumo markers in cervical cancer patients. J Biochem Mol Biol Biophys 6: 387-390.

80. Subapriya R, Kumaraguruparan R, Ramachandran CR, Nagini S (2002) Oxidant-antioxidant status in patients with oral squamous cell carcinomas at different intraoral sites. Clin Biochem 35: 489-493.

81. Morabito F, Cristani M, Saija A, Stelitano C, Callea V, et al. (2004) Lipid peroxidation and protein oxidation in patients affected by Hodgkin's lymphoma. Mediators Inflamm 13: 381-383.

82. Yeh CC, Hou MF, Tsai SM, Lin SK, Hsiao JK, et al. (2005) Superoxide anion radical, lipid peroxides and antioxidant status in the blood of patients with breast cancer. Clin Chim Acta 361: 104-111.

83. Aydin A, Arsova-Sarafinovska Z, Sayal A, Eken A, Erdem O, et al. (2006 Oxidative stress and antioxidant status in non-metastatic prostate cancer and benign prostatic hyperplasia. Clin Biochem 39: 176-179.

84. Ahmad I, Zafaryab M, Al-Fatlawi AA, Kazim Z, Perwez A, et al. (2013) Modulation of proton pumping ATPase activity of probiotic Lactobacilli by dietary cucurbits. Journal of Proteins and Proteomics 4: 217-222.

85. Knackstedt RW, Moseley VR, Wargovich MJ (2012) Anticancer Agents Med Chem 12: 1203-1210.

86. Meixia Z, Chunyan S, Xiaolei S, Xiaolin Y, Jesse LL, et al. (2010) Inhibition of pancreatic cancer cell growth by cucurbitacin $B$ through modulation of signa transducer and activator of transcription 3 Signaling. Pancreas 39: 923-929.

87. Fotsis T, Pepper MS, Aktas E, Breit S, Rasku S, et al. (1997) Flavonoids, dietary-derived inhibitors of cell proliferation and in vitro angiogenesis. Cancer Res 57: 2916-2921.

88. Wang W, Van APC, Irons KA, Chen S, Stewart JW, et al. (2004) Individual and interactive effects of apigenin analogs on $\mathrm{G} 2 / \mathrm{M}$ cell-cycle arrest in human colon carcinoma cell lines. Nutr Cancer 48: 106-114.

89. Wang IK, Lin-Shiau SY, Lin JK (1999) Induction of apoptosis by apigenin and related flavonoids through cytochrome $c$ release and activation of caspase- 9 and caspase-3 in leukaemia HL-60 cells. Eur J Cancer 35: 1517-1525.

90. Shukla S, Gupta S (2004) Molecular mechanisms for apigenin-induced cellcycle arrest and apoptosis of hormone refractory human prostate carcinoma DU145 cells. Mol Carcinog 39: 114-126.

91. Yin F, Giuliano AE, Van HAJ (1999) Growth inhibitory effects of flavonoids in human thyroid cancer cell lines. Thyroid 9: 369-376.

92. Li B, Birt DF (1996) In vivo and in vitro percutaneous absorption of cance preventive flavonoid apigenin in different vehicles in mouse skin. Pharm Res (NY) 13: 1710-1715

93. Yin F, Giuliano AE, Law RE, Van HAJ (2001) Apigenin inhibits growth and induces $\mathrm{G} 2 / \mathrm{M}$ arrest by modulating cyclin-CDK regulators and ERK MAP kinase activation in breast carcinoma cells. Anticancer Res 21: 413-420.

94. Liu LZ, Fang J, Zhou Q, Hu X, Shi X, et al. (2005) Apigenin inhibits expression of vascular endothelial growth factor and angiogenesis in human lung cancer cells: implication of chemoprevention of lung cancer. Mol. Pharmacol 68: 635-643.

95. Wang QR, Yao XQ, Wen G, Fan Q, Li YJ, et al. (2011) Apigenin suppresses the growth of colorectal cancer xenografts via phosphorylation and up-regulated FADD expression. Oncology Letters 2: 43-47.

96. lizumi Y, Oishi M, Taniguchi T, Goi W, Sowa Y, et al. (2013) The flavonoid apigenin downregulates CDK1 by directly targeting ribosomal protein S9. Plose one 8: 73218-73219.

97. Shukla S, Gupta S (2010) Apigenin: A promising molecule for cancer prevention. Pharm Res 27: 962-978.

98. Alyasiri NS, Ali A, Kazim Z, Gupta S, Mandal AK, et al. (2013) Aberrant promoter methylation of PTEN gene among Indian patients with oral squamous cell carcinoma. Int J Biol Markers 28: 298-302.

99. Rizvi MMA, Alam MS, Ali A, Mehdi SJ, Batra S, et al. (2011) Aberrant promote methylation and inacivation of PTEN gene in cervical carcinoma from northern Indian population. J Cancer Res Clin Oncol 137: 1255-1262.

100. Rizvi MMA, Ali A, Mehdi SJ, Saluja SS, Mishra PK (2013) Association of epigenetic alteration in PTEN gene with colorectal cancer progression among Indian population. Int J Colorectal Dis 28: 283-284.

101. Link A, Balaguer F, Shen Y, Lozano JJ, Leung HC, et al. (2013) Curcumin modulates DNA methylation in colorectal cancer cells. PLoS One 8: 57709e.

102. Fang MZ, Wang Y, Ai N, Hou Z, Sun Y, et al. (2003) Tea polypheno (2)-epigallocatechin-3-gallate inhibits DNA methyltransferase and reactivates methylation-silenced genes in cancer cell lines. Cancer Res 63: 7563-7570.

103. Fang MZ, Chen D, Sun Y, Jin Z, Christman JK, et al. (2005) Reversal of hypermethylation and reactivation of p16INK4a, RARbeta, and MGMT genes by genistein and other isoflavones from soy. Clin Cancer Res 11: 7033-7041. 
Citation: Ahmad I, Nasiruddin M, Khan MA, Zafaryab M, Mehdi SH, et al. (2016) Nutraceuticals as Chemopreventive and Therapeutic agents in Gut Associated Pathogenesis. Biochem Anal Biochem 5: 298. doi: 10.4172/2161-1009.1000298

104. Majid S, Dar AA, Shahryari V, Hirata H, Ahmad A, et al. (2010) Genistein reverses hypermethylation and induces active histone modifications in tumor suppressor gene B-Cell translocation gene 3 in prostate cancer. Cancer 116: 66-76.

105. Morimoto T, Sunagawa Y, Kawamura T, Takaya T, Wada H, et al. (2008) The dietary compound curcumin inhibits p300 histone acetyltransferase activity and prevents heart failure in rats. J Clin Invest 118: 868-878.

106. Jha AK, Nikbakht M, Parashar G, Shrivastava A, Capalash N, et al. (2010) Reversal of hypermethylation and reactivation of the RARbeta2 gene by natural compounds in cervical cancer cell lines. Folia Biol (Praha) 56: 195-200.

107.Kuck D, Singh N, Lyko F, Medina-Franco JL (2010) Novel and selective DNA methyltransferase inhibitors: Docking-based virtual screening and experimental evaluation. Bioorg Med Chem 18: 822-829.

108. Liu Z, Xie Z, Jones W, Pavlovicz RE, Liu S, et al. (2009) Curcuminis a potent DNA hypomethylation agent. Bioorg Med Chem Lett 19: 706-709.

109. Shu L, Khor TO, Lee JH, Boyanapalli SS, Huang Y, et al. (2011) Epigenetic CpG demethylation of the promoter and reactivation of the expression of Neurog-1 by curcumin in prostate LNCaP cells. AAPS $\mathrm{J}$ 13: 606-614.

110. Fuand S, Kurzrock R (2010) Development of curcumin as an epigenetic agent. Cancer 116: 4670-4676.

111. Chen Y, Shu W, Chen W, Wu Q, Liu H, et al. (2007) Curcumin, both histone deacetylase and p300/CBP-specific inhibitor, represses the activity of nuclear factor kappa B and Notch 1 in Raji cells. Basic Clin Pharmacol Toxicol 101: 427-433.

112. Kikuno N, Shiina H, Urakami S, Kawamoto K, Hirata H, et al. (2008) Genistein mediated histone acetylation and demethylation activates tumor suppressor genes in prostate cancer cells. Int J Cancer 123: 552-560.

113. Tsang WP, Kwok TT (2010) Epigallocatechin gallate up-regulation of miR-16 and induction of apoptosis in human cancer cells. J Nutr Biochem 21: 140-146.
114. Li Y, Yuan YY, Meeran SM, Tollefsbol TO (2010) Synergistic epigenetic reactivation of estrogen receptor-a (ERa) by combined green tea polyphenol and histone deacetylase inhibitor in ERa-negative breast cancer cells. Mol Cancer 9: 274

115. Fini L, Selgrad M, Fogliano V, Graziani G, Romano M, et al. (2007) Annurca apple polyphenols have potent demethylating activity and can reactivate silenced tumor suppressor genes in colorectal cancer cells. J Nutr 137: 2622-2628.

116. Baur JA (2010) Resveratrol, sirtuins, and the promise of a DR mimetic. Mech Ageing Dev 131: 261-269.

117. Acharya MR, Sparreboom A, Venitz J, Figg WD (2005) Rational development of histone deacetylase inhibitors as anticancer agents: A review. Mol Pharmacol 68: 917-932.

118. Marks PA, Richon VM, Miller T, Kelly WK (2004) Histone deacetylase inhibitors. Adv Cancer Res 91: 137-168.

119. Oldenburg M, Krüger A, Ferstl R, Kaufmann A, Nees G, et al. (2012) TLR13 recognizes bacterial $23 S$ rRNA devoid of erythromycin resistance-forming modification. Science 337: 1111-1115.

120. Mali P, Chou BK, Yen J, Ye Z, Zou J, et al. (2010) Butyrate greatly enhances derivation of human induced pluripotent stem cells by promoting epigenetic remodeling and the expression of pluripotencyassociated genes. Stem Cells 28: $713-720$.

121. Kida Y, Shimizu T, Kuwano K (2006) Sodium butyrate up-regulates cathelicidin gene expression via activator protein-1 and histone acetylation at the promoter region in a human lung epithelial cell line, EBC-1. Mol Immunol 43: 1972-1981.

122. Singh N, Thangaraju M, Prasad PD, Martin PM, Lambert NA, et al. (2010) Blockade of dendritic cell development by bacterial fermentation products butyrate and propionate through a transporter (Slc5a8)-dependent inhibition of histone deacetylases. J Biol Chem 285: 27601-27608. 